\title{
Retrospective analysis of factors associated with aortic remodeling in patients with Stanford type B aortic dissection after thoracic endovascular aortic repair
}

Biao $Y u^{1,2}$, Tangzhiming $\mathrm{Li}^{1,2}$ and Huadong $\mathrm{Liu}^{1,2^{*}}$

\begin{abstract}
Objective: Acute aortic dissection is a life-threatening condition. Thoracic endovascular aortic repair (TEVAR), together with optimized medical treatment, is currently the first line treatment for acute Stanford type B aortic dissection. TEVAR can close the entry tear and reduce mortality. Aortic remodeling after TEVAR can directly affect the patient's long-term prognosis. The factors that influence aortic remodeling have, however, received insufficient clinical attention and remain unclear. It is very important to identify these factors.
\end{abstract}

Methods: A total of 100 patients were continuously enrolled from 2011 to 2018 in 2 centers. Relevant data, including time from hospital admission to surgery, medicine use and aortic computed tomography angiography images obtained before and 6 months after surgery were collected. Patients were divided into favorable and adverse aortic remodeling groups, according to the degree of aortic remodeling. Analysis of variance and the chisquare test were performed using SPSS software to compare differences between groups and to determine the factors that influence postoperative aortic remodeling.

Results: The proportion of single-stent implantations was higher in the favorable remodeling group than in the adverse remodeling group (79.5\% vs. $53.8 \%$ in distal end of stent-graft level and $81.3 \%$ vs. $56.4 \%$ in diaphragm level, respectively, $p<0.05$ ). The earlier the TEVAR procedure was performed, the better the aortic remodeling (3.4 days vs. 4.8 days in distal stent graft levels, and 3.6 days vs. 4.9 days in diaphragm level, respectively, $p<0.05$ ), the presence of residual distal entry tears in the abdominal aorta also improved aortic remodeling after TEVAR $(85.7 \%$ vs. $55.1 \%$ in the celiac trunk level, and $92.0 \%$ vs. $48.9 \%$ in the right renal artery level, respectively, $p<0.05$ ).

Conclusion: Single stent-graft implantation and early surgery were associated with favorable aortic remodeling. Distal entry tears were also conducive to aortic remodeling after surgery for aortic dissection.

Keywords: Type B aortic dissection, Thoracic endovascular aortic repair, Aortic remodeling

\footnotetext{
* Correspondence: Ihd2578@163.com

${ }^{1}$ The Second Clinical Medical College, Jinan University, 1017 Dongmen North

Road, Shenzhen 518020, Guangdong, China

${ }^{2}$ The First Affiliated Hospital, Southern University of Science and Technology (Department of Cardiology, Shenzhen Cardiovascular Minimally Invasive Medical Engineering Technology Research and Development Center, Shenzhen People's Hospital), Shenzhen 518020, Guangdong, China
}

(c) The Author(s). 2021 Open Access This article is licensed under a Creative Commons Attribution 4.0 International License, which permits use, sharing, adaptation, distribution and reproduction in any medium or format, as long as you give appropriate credit to the original author(s) and the source, provide a link to the Creative Commons licence, and indicate if changes were made. The images or other third party material in this article are included in the article's Creative Commons licence, unless indicated otherwise in a credit line to the material. If material is not included in the article's Creative Commons licence and your intended use is not permitted by statutory regulation or exceeds the permitted use, you will need to obtain permission directly from the copyright holder. To view a copy of this licence, visit http://creativecommons.org/licenses/by/4.0/. The Creative Commons Public Domain Dedication waiver (http://creativecommons.org/publicdomain/zero/1.0/) applies to the data made available in this article, unless otherwise stated in a credit line to the data. 


\section{Highlights}

Data, including baseline clinical parameters, complications, treatment administered during hospitalization and details of surgical procedures, were collected from multiple medical centers for 100 patients who underwent thoracic endovascular aortic repair (TEVAR) and their association with successful vascular remodeling was carefully evaluated.

Single stent-graft implantation, early surgery and distal entry tear are associated with favorable aortic remodeling.

\section{Introduction}

Aortic dissection is a life-threatening condition caused by a tear in the inner layer of the aorta, which results in a separation of the layers of the aortic wall and subsequent formation of a true lumen and a false lumen [1]. In recent years, acute aortic dissection has become a major public health burden, with increased incidence and younger age of onset resulting in extremely high mortality and disability rates.

Based on anatomical location, aortic dissection can be classified as Stanford type A (affects the ascending aorta) or Stanford type B (begins beyond the brachiocephalic vessels). For type B aortic dissection, the in-hospital mortality is as high as $10.7 \%$ [2], with most deaths due to complications of aortic dissection [3], including lethal malperfusion, aortic insufficiency, heart failure and stroke [4]. Thoracic endovascular aortic repair (TEVAR) is the first choice of treatment for acute type $B$ aortic dissection (ATBAD) [5, 6]. Increasing evidences suggest that TEVAR has significant advantages over open surgery in patients with ATBAD [7, 8].

Favorable vascular remodeling is the process of reducing the volume of the false cavity of the aortic dissection after TEVAR. Favorable vascular remodeling refers to a more stable structure of the vascular false cavity. Generally speaking, the greater change in CT value, the better the vascular remodeling. In contrast, adverse aortic remodeling is in opposite.

Simple TEVAR does not, however, guarantee favorable remodeling and the factors that influence long-term aortic remodeling in patients are currently not well understood. Identification of potential characters in baseline clinical characteristics or clinical treatment between patients with favorable and adverse aortic remodeling after TEVAR may play a vital role in predicting the prognosis of patients.

\section{Methods}

\section{Study population}

We retrospectively reviewed clinical data for 178 patients with ATBAD who underwent TEVAR in Shenzhen People's Hospital and Guangdong Provincial
People's Hospital from January 2011 to December 2018. Aortic remodeling after TEVAR was analyzed using preand post-operative aortic computed tomography angiography (CTA) and 100 patients with complete data were included in the final analysis.

\section{Data collection and definitions}

Patient data, sex, age, time of hospital admission, time from admission to surgery, medication use( $\beta$-blockers/ ACEI/ ARB/ CCB/ Aspirin), complications (Pleural effusion), presence or absence of endoleaks after surgery, and surgical methods, were collected. Endoleaks near both the entry tear and aortic stent graft were recorded in this study. Aortic bare stents are special stents that are not coated with drugs and membrane. The corresponding variable is a conventional stent covered with a membrane. Surgical methods included single stent-graft implantation (placement of a single aortic stent-graft) and complex stent-graft implantation (placement of $\geq 2$ stent-grafts). According to guideline recommendations [9], all patients underwent CTA before and 6 months after surgery. Aortic CTA data were collected and used to assess aortic remodeling at different levels (left subclavian artery, distal edge of stent-graft, left ventricle, diaphragm, celiac trunk and right renal artery.).

\section{Assessment of aortic remodeling based on aortic CTA images}

After aortic dissection, the shape of the true and false lumens was irregular. Measurements of the area at different levels can be converted into mean minimum and maximum diameters of the true or false lumens [10]. The change in the mean diameters of the two lumens better reflected the degree of aortic remodeling within a few months after surgery for dissection. Changes in diameter were measured at six levels: left subclavian artery, distal end of stent-graft, left ventricle, diaphragm, celiac trunk, and right renal artery . The degree of aortic remodeling was determined by the changes in the ratio of false lumen to total aortic diameter before and after surgery. The mean diameters of the true and the false lumens were measured, and the ratio of false lumen to total aortic diameter was calculated according to the following formula: mean diameter of false lumen/ mean diameter of false lumen +mean diameter of true lumen. The degree of aortic remodeling was determined according to the changes in the ratio of false lumen to total aortic diameter before and after surgery.

\section{Statistical analysis}

Differences between patients with favorable and adverse aortic remodeling were analyzed using SPSS statistical software. Categorical variables were analyzed using the chi-square test and are presented as percentages. 
Continuous variables were analyzed using analysis of variance (ANOVA) and are expressed as means \pm standard deviation (SD). In both cases, $p<0.05$ was considered to be statistically significant.

\section{Results}

178 patients with ATBAD were continuously enrolled from 2011 to 2018 (Fig. 1). The patients received optimal medicine upon hospital admission and underwent TEVAR when their basal blood pressure was controlled within a reasonable range (systolic blood pressure 100$120 \mathrm{mmHg}$ ). All patients were followed up for at least 6 months. 100 patients were included in the final analysis.

No significant differences were found in medicine use (angiotensin converting enzyme inhibitors, angiotensin receptor blockers, $\beta$-blockers, calcium channel blockers, and aspirin), the presence or absence of pleural effusion or D-dimer levels between the favorable and unfavorable aortic remodeling groups $(p>0.05)$ (supplemental files).

CTA images acquired before and 6 months after surgery were used to evaluate the degree of aortic remodeling. Among 100 patients with ATBAD, six different levels were chosen for sections: left subclavian artery, distal end of stent-graft, left ventricle, diaphragm, celiac trunk and right renal artery. The cross-sectional diameters of the true and false lumens at the six levels were calculated, and the ratio of false lumen to total aortic diameter was then calculated.

CTA images before and 6 months after surgery indicated a significant difference in healing of the false lumen between patients with favorable and adverse aortic remodeling. In patients with favorable aortic

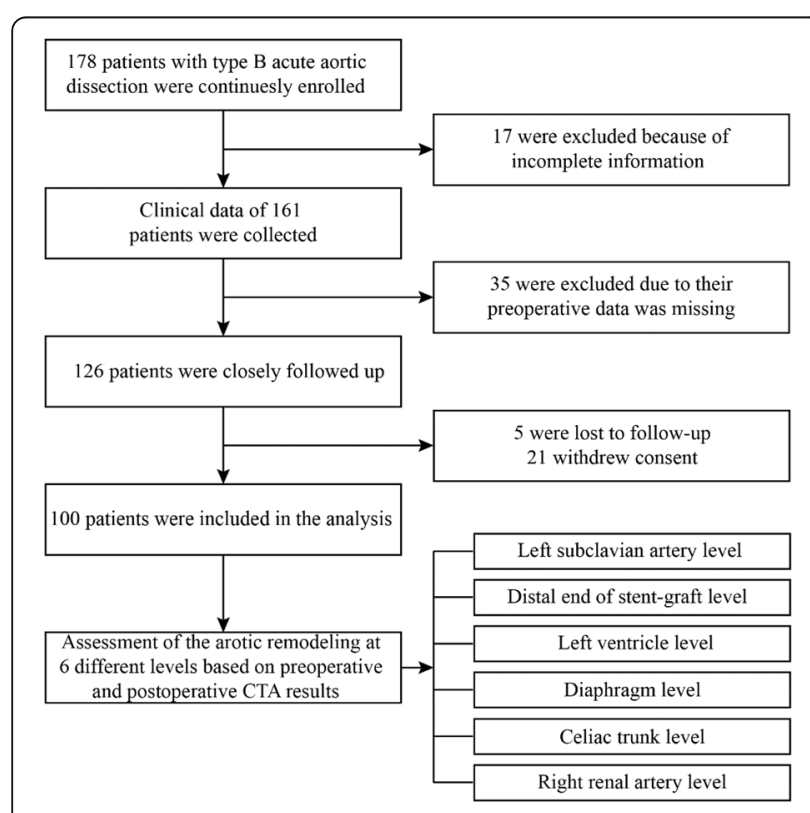

Fig. 1 Study flow chart of included patients remodeling at the diaphragm level, the false lumen had almost disappeared 6 months after surgery (Fig. 2A and B) and outcomes were significantly improved. Poor postoperative aortic remodeling at the diaphragm level was associated with obviously enlarged hematoma and slightly increased ipsilateral pleural effusions (Fig. 2E and F). The postoperative recovery of these patients was poor and they required close follow up, with control of blood pressure and heart rate, to prevent serious vascular complications.

Identification of factors associated with favorable aortic remodeling is important to evaluate the long-term prognosis of patients. We further analyzed differences in baseline clinical data and surgical conditions between patients with aortic dissection at the six different levels who had favorable and adverse aortic remodeling. Because of differences in entry tears and artery involvement, the effective number of patients with aortic dissections at the levels of the left subclavian artery, the distal end of the stent-graft, the left ventricle, the

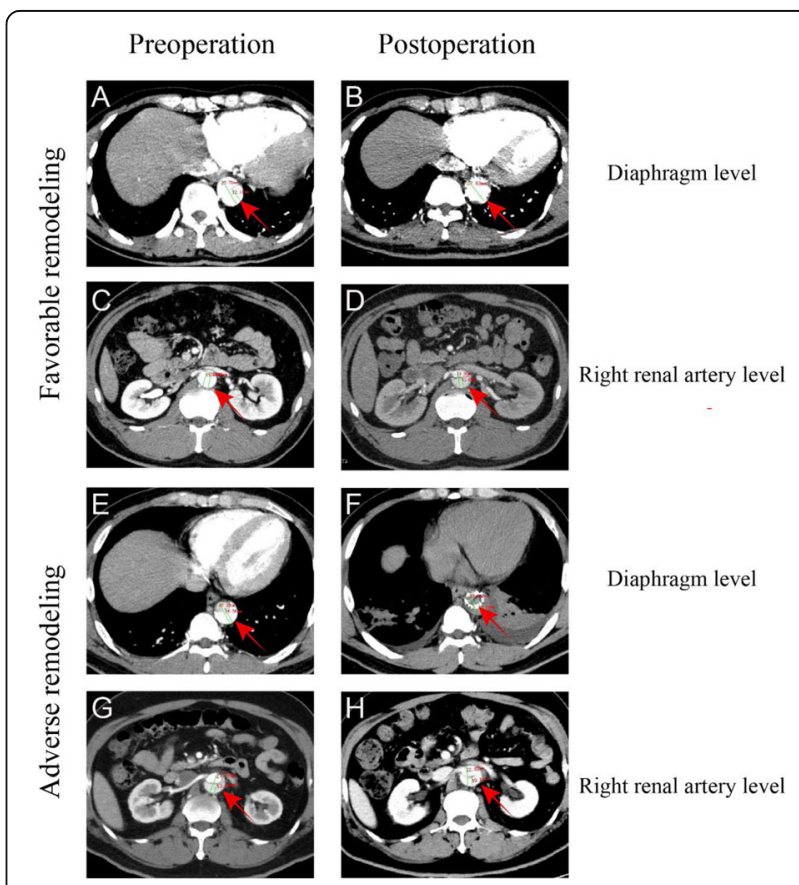

Fig. $2 C T$ images, before surgery and after TEVAR, showing favorable and adverse aortic remodeling. A and B: Favorable aortic remodeling before and after surgery observed at the diaphragm level. The false lumen had almost disappeared. C and D: Favorable aortic remodeling before and after surgery observed at the level of the right renal artery. The false lumen had almost disappeared. E and F: Adverse aortic remodeling before and after surgery observed at the diaphragm level. The false lumen obviously enlarged. $\mathrm{G}$ and $\mathrm{H}$ : Adverse aortic remodeling before and after surgery observed at the level of the right renal artery. The false lumen had no obviously change after 6 months. Red arrows indicate the location of dissected lesions 
diaphragm, the celiac trunk and the right renal artery were $12,78,95,96,99$ and 96, respectively.

Aortic remodeling after surgery was found to be closely associated with time from hospital admission to surgery, surgical method and patency of distal entry tears. As shown in Table 1, at the levels of the distal end of the stent-graft and the diaphragm, a higher proportion of patients who received single-stent implantation had favorable aortic remodeling after surgery, compared with those who received complex stent-graft implantation $(79.5 \%$ vs. $53.8 \%, p<0.05$ and $81.3 \%$ vs. $56.3 \%$, respectively, $p<0.05)$. Patients who underwent surgery soon after admission also had better aortic remodeling than those who underwent late surgery $(3.4 \pm 2.5$ vs. $4.8 \pm 3.4, p<0.05$ and $3.6 \pm 2.6$ vs. $4.9 \pm 3.2, p<0.05)$. At the levels of the celiac trunk and right renal artery, better remodeling with present distal tears $(85.7 \%$ vs. 55.1 and $92.0 \%$ vs. $48.9 \%$, respectively, $p<0.05)$. The

Table 1 Data showing influencing factors between groups at difference levels

\begin{tabular}{|c|c|c|c|c|c|}
\hline Level of aortic dissection & Variable & $\begin{array}{l}\text { Total } \\
\text { number }\end{array}$ & $\begin{array}{l}\text { Favorable aortic } \\
\text { remodeling }\end{array}$ & $\begin{array}{l}\text { adverse aortic } \\
\text { remodeling }\end{array}$ & $\begin{array}{l}p \\
\text { value }\end{array}$ \\
\hline \multirow{4}{*}{$\begin{array}{l}\text { Left subclavian artery Level (total } n=12, \\
n=6 \text { in each group) }\end{array}$} & Aortic bare stent placement (n (\%)) & $0(0 \%)$ & $0(0 \%)$ & $0(0 \%)$ & 1 \\
\hline & Endoleak (n (\%)) & $0(0 \%)$ & $0(0 \%)$ & $0(0 \%)$ & 1 \\
\hline & $\begin{array}{l}\text { Surgical method (placement of one } \\
\text { single stent-graft, } \mathrm{n}(\%))\end{array}$ & 7 (58.3\%) & $4(66.7 \%)$ & $3(50 \%)$ & 0.558 \\
\hline & $\begin{array}{l}\text { Time from admission to surgery (mean } \\
\text { days } \pm S D \text { ) }\end{array}$ & $5.3 \pm 3.6$ & $4.8 \pm 3.7$ & $5.7 \pm 8$ & 0.708 \\
\hline \multirow[t]{4}{*}{$\begin{array}{l}\text { Distal end of stent-graft Level (total } n= \\
79, n=39 \text { in each group) }\end{array}$} & Aortic bare stent placement $(\mathrm{n}(\%))$ & $\begin{array}{l}11 \\
(14.1 \%)\end{array}$ & $5(12.8 \%)$ & $6(15.4 \%)$ & 0.745 \\
\hline & Endoleak (n (\%)) & $\begin{array}{l}10 \\
(12.8 \%)\end{array}$ & $4(10.3 \%)$ & $6(15.4 \%)$ & 0.498 \\
\hline & $\begin{array}{l}\text { Surgical method (placement of single } \\
\text { stent graft, } \mathrm{n}(\%) \text { ) }\end{array}$ & $\begin{array}{l}52 \\
(66.7 \%)\end{array}$ & $31(79.5 \%)$ & $21(53.8 \%)$ & 0.016 \\
\hline & $\begin{array}{l}\text { Time from admission to surgery } \\
\text { (mean } \pm \mathrm{SD} \text { ) }\end{array}$ & $4.1 \pm 3.0$ & $3.4 \pm 2.5$ & $4.8 \pm 3.4$ & 0.028 \\
\hline \multirow[t]{3}{*}{$\begin{array}{l}\text { Left ventricle Level (total } n=95, n=48 \text { and } \\
47 \text { in each group) }\end{array}$} & Aortic bare stent placement (n (\%)) & $\begin{array}{l}11 \\
(11.6 \%)\end{array}$ & $6(12.5 \%)$ & $5(10.6 \%)$ & 0.777 \\
\hline & $\begin{array}{l}\text { Surgical method (placement of single } \\
\text { stent graft, } \mathrm{n}(\%) \text { ) }\end{array}$ & $\begin{array}{l}65 \\
(68.4 \%)\end{array}$ & $34(70.8 \%)$ & $31(66 \%)$ & 0.609 \\
\hline & $\begin{array}{l}\text { Time from admission to surgery } \\
\text { (mean } \pm \text { SD) }\end{array}$ & $4.2 \pm 3.0$ & $4.4 \pm 3.1$ & $4.0 \pm 2.8$ & 0.587 \\
\hline \multirow[t]{3}{*}{$\begin{array}{l}\text { Diaphragm Level (total } n=96, n=48 \text { in } \\
\text { each group) }\end{array}$} & Aortic bare stent placement (n (\%)) & $\begin{array}{l}11 \\
(11.5 \%)\end{array}$ & $6(12.5 \%)$ & $5(10.4 \%)$ & 0.749 \\
\hline & $\begin{array}{l}\text { Surgical method (placement of single } \\
\text { sent graft, } n(\%) \text { ) }\end{array}$ & $\begin{array}{l}66 \\
(68.8 \%)\end{array}$ & $39(81.3 \%)$ & $27(56.3 \%)$ & 0.008 \\
\hline & $\begin{array}{l}\text { Time from admission to surgery } \\
\text { (mean } \pm \text { SD) }\end{array}$ & $4.2 \pm 2.9$ & $3.6 \pm 2.6$ & $4.9 \pm 3.2$ & 0.031 \\
\hline \multirow[t]{4}{*}{$\begin{array}{l}\text { Celiac trunk Level (total } n=99, n=50 \text { and } \\
49 \text { in each group) }\end{array}$} & Aortic bare stent placement $(\mathrm{n}(\%))$ & $\begin{array}{l}11 \\
(11.1 \%)\end{array}$ & $6(12 \%)$ & $5(10.2 \%)$ & 0.776 \\
\hline & $\begin{array}{l}\text { Surgical method (placement of single } \\
\text { sent graft, } \mathrm{n}(\%) \text { ) }\end{array}$ & $\begin{array}{l}66 \\
(66.7 \%)\end{array}$ & $32(64 \%)$ & $34(69.4 \%)$ & 0.570 \\
\hline & $\begin{array}{l}\text { Time from admission to surgery } \\
\text { (mean } \pm \text { SD) }\end{array}$ & $4.3 \pm 3.0$ & $4.4 \pm 3.0$ & $4.2 \pm 3.0$ & 0.720 \\
\hline & Distal entry tears (presence, $\mathrm{n}(\%)$ ) & $\begin{array}{l}69 \\
(70.4 \%)\end{array}$ & $42(85.7 \%)$ & $27(55.1 \%)$ & 0.000 \\
\hline \multirow[t]{4}{*}{$\begin{array}{l}\text { Right renal artery Level (total } n=96, n=48 \\
\text { in each group) }\end{array}$} & Aortic bare stent placement (n (\%)) & $\begin{array}{l}11 \\
(11.5 \%)\end{array}$ & $8(16.7 \%)$ & $3(6.3 \%)$ & 0.109 \\
\hline & $\begin{array}{l}\text { Surgical methods (placement of single } \\
\text { sent graft, } n(\%) \text { ) }\end{array}$ & $\begin{array}{l}64 \\
(66.7 \%)\end{array}$ & $34(70.8 \%)$ & $30(62.5 \%)$ & 0.386 \\
\hline & $\begin{array}{l}\text { Time from admission to surgery } \\
\text { (mean } \pm \text { SD) }\end{array}$ & $4.3 \pm 3.0$ & $4.5 \pm 3.2$ & $4.1 \pm 2.9$ & 0.546 \\
\hline & Distal entry tears (presence, $\mathrm{n}(\%)$ ) & $\begin{array}{l}69 \\
(71.1 \%)\end{array}$ & $46(92.0 \%)$ & $23(48.9 \%)$ & 0.000 \\
\hline
\end{tabular}


association between endoleaks and aortic remodeling was only analyzed at the levels of the subclavian artery and the distal end of the stent-graft because endoleaks only affected the proximal stent attachment site. There was no significant association between endoleaks and aortic remodeling at the level of the distal end of the stent-graft ( $12.8 \%$ vs. $10.3 \%, p>0.05)$.

\section{Discussion}

Our study provided further clinical evidence that strengthens guidance for the management of patients during hospitalization and showed that performing surgery as soon as possible promoted better aortic remodeling. We found that single stent-graft implantation and distal entry tear are associated with favorable aortic remodeling.

Favorable aortic remodeling significantly improves the prognosis of patients with aortic dissection after surgery. Previous studies showed that the 3-year mortality of patients with an enlarged vascular lumen caused by insufficient thrombosis of the false lumen and poor vascular remodeling after TEVAR tends to be higher [11]. This means that the degree of false lumen thrombosis and vascular remodeling will directly affect the prognosis of patients with aortic dissection after surgery [12, 13]. A previous study, which focused more on investigating aortic remodeling in patients with acute and chronic aortic dissection after TEVAR, showed that TEVAR cannot help to improve aortic remodeling in patients with chronic aortic dissection [14]. There have, however, been very few reports describing the differences in surgical effect and prognosis of patients with acute aortic dissection who underwent TEVAR, leading to a lack of guidance for the management of patients with ATBAD who were hospitalized for stent graft-implantation.

In this study, there was no significant difference in baseline data, including age, blood pressure, medication use, endoleaks and Aortic bare stent implements between patients in the favorable and adverse aortic remodeling groups, indicating good consistency between the two groups.

We found that one single stent-graft implantation and a shorter time from hospital admission to the TEVAR procedure were associated with a good prognosis. We believe that this may because of good vascular condition and better control of risk factors, such as hypertension, have a positive effect on favorable aortic remodeling. It is generally believed that this type of patient has a relatively simple condition, fewer complications and better postoperative prognosis. Following hospital admission, early surgery for patients with aortic dissection can promote favorable aortic remodeling. Closure of the entry tears may lead to rapid healing and remodeling of the dissected aorta [1]. When surgery is delayed, the vascular lesion worsens and it may be difficult to completely cover the false lumen [15]. Our findings are consistent with previous studies [16, 17], which showed that delayed surgery has an adverse effect on the prognosis of patients with acute aortic dissection after maintaining a stable internal environment by administering adequate medical treatment [2].

Performing TEVAR during the acute phase of aortic dissection can promptly seal off entry tears and prevent blood flow into the false lumen, leading to thrombosis of the false lumen and thereby enlarging the true lumen and stimulating aortic remodeling [18]. Based on optimized medical treatment, performing TEVAR as early as possible can, therefore, prevent blood flow into the aortic wall, enlarge the true lumen and mitigate poor dynamic blood perfusion of the viscera and lower extremities. On the other hand, collapse of the false lumen avoids insufficient thrombosis caused by continuous impingement of blood flow on the false lumen and ultimately affects vascular remodeling after the operation. With no blood flow at the distal end of the false cavity, the organization of the thrombus begins to appear within 1 or 2 days [19].

Distal aortic remodeling is controlled by blood flow between the true and false lumens as well as by pressure in the false lumen. High pressure in the false lumen can lead to poor aortic remodeling [20]. In patients with aortic dissection, if the intimal tear is confined to the thoracic aorta and there is no patent entry tear in the abdominal aortic segment, a false lumen would not exist in the abdominal aortic segments after the entry tear of the dissection is completely covered by a stent-graft. However, if the entry tear is not completely covered by the stent-graft and there is also no patent entry tear in the abdominal aorta, the pressure in the false lumen would be higher than in those with a patent distal tear after covering the proximal intimal tear [21]. This can lead to incomplete thrombosis in the false lumen, thereby affecting remodeling in distal aorta. Aortic remodeling of the abdominal aorta is, therefore, associated with the presence or absence of a patent entry tear in the abdominal aorta. To achieve better postoperative aortic remodeling in patients who do not have distal entry tears, it is necessary to strictly control blood pressure before the stent-graft implantation and to regularly follow-up by CT examination to observe the remodeling of the abdominal aorta after surgery.

In this study, we found that endoleak after TEVAR had little effect on aortic remodeling. This may be because of the low incidence of endoleak in patients included in this study (only 1\%). Endoleak can increase blood flow in the false lumen, thus increasing the pressure inside the false lumen and slowing remodeling of the aorta. Although endoleak is a surgical adverse event 
that should be avoided, most endoleaks are self-limiting. Only severe endoleaks impinge on blood flow in the proximal blood vessels, which aggravates the patient's condition [22] and can even cause traumatic thoracic aortic injury [23]. Endoleaks thus have no obvious guiding significance for the management of patients with ATBAD.

This study had some limitations that should be borne in mind. Because it was a retrospective study, we cannot establish a cohort for specific interventions. The number of patients enrolled in the group was limited. we need to boost more credibility in further research. The incidence of endoleaks was also low, so the factors affecting aortic remodeling after surgery in patients with ATBAD could not be fully elucidated. Further prospective studies with larger sample sizes are needed to confirm the relationship between the time of operation, aortic remodeling and the prognosis of patients with ATBAD after surgery.

\section{Conclusions}

Our study had four main findings. 1) For patients with uncomplicated acute aortic dissection, the entry tears could be closed by placing a single stent-graft, and these patients were more likely to have better aortic remodeling. 2) Once the patient's blood pressure was reduced below the normal range by optimal medical treatment, the earliest possible TEVAR resulted in more complete thrombosis formation in the false lumen and better aortic remodeling. 3) In the distal end of aortic dissection which was not covered by the stent graft, aortic remodeling was associated with the presence or absence of a patent distal entry tear. It was, therefore, important that patients without a distal entry tear received antihypertensive treatment before surgery.

\section{Abbreviations}

TEVAR: Thoracic endovascular aortic repair; ATBAD: Acute Stanford type B aortic dissection; CTA: Computed tomography angiography; ANOVA: Analysis of variance; SD: Standard deviation

\section{Supplementary Information}

The online version contains supplementary material available at https://doi. org/10.1186/s13019-021-01571-2.

Additional file 1.

\section{Acknowledgments}

This work was supported by the Department of Cardiology, Shenzhen Cardiovascular Minimally Invasive Medical Engineering Technology Research and Development Center, Shenzhen Peoples Hospital.

Standards for research in complementary and alternative medicine Not applicable.

Authorship

Biao Yu and Tangzhiming Li contributed equally to this work.

\section{Authors' contributions}

Huadong Liu designed the study and submitted the manuscript. Biao Yu collected and analyzed data, Biao Yu and Tangzhiming Li drafted the article together. All authors read and approved the final manuscript.

\section{Funding}

Science and Technology Planning Project of Shenzhen Municipality. KCXFZ202002011009124 Huadong Liu.

Science and Technology Planning Project of Shenzhen Municipality. JCYJ20190806153207263 Huadong Liu.

The National Natural Science Foundation of China, No. 82000058,

Tangzhiming Li.

\section{Availability of data and materials}

The datasets used or analysed during the current study are available from the corresponding author on reasonable request.

\section{Declarations}

Ethics approval and consent to participate

Not applicable.

Consent for publication

Not applicable.

\section{Competing interests}

The authors declare that they have no competing interests.

Received: 30 March 2021 Accepted: 28 June 2021

Published online: 07 July 2021

\section{References}

1. Nienaber CA, Clough RE, Sakalihasan N, Suzuki T, Gibbs R, Mussa F, et al. Aortic dissection. Nat Rev Dis Primers. 2016;2(1):16053. https://doi.org/10.103 8/nrdp.2016.53.

2. Hagan PG, Nienaber CA, Isselbacher EM, Bruckman D, Karavite DJ, Russman $\mathrm{PL}$, et al. The International Registry of Acute Aortic Dissection (IRAD): new insights into an old disease. JAMA. 2000;283:897-903.

3. Fattori R, Tsai TT, Myrmel T, Evangelista A, Cooper JV, Trimarchi S, et al. Complicated acute type B dissection: is surgery still the best option?: a report from the international registry of acute aortic dissection. JACC Cardiovasc Interv. 2008;1(4):395-402. https://doi.org/10.1016/j.jcin.2008.04. 009.

4. Nienaber CA, Clough RE. Management of acute aortic dissection. Lancet 2015;385(9970):800-11. https://doi.org/10.1016/S0140-6736(14)61005-9.

5. 2014 ESC guidelines on the diagnosis and treatment of aortic diseases. Eur Heart J. 2014;35(41):2873-926. https://doi.org/10.1093/eurheartj/ehu281.

6. Riambau V, Böckler D, Brunkwall J, Cao P, Chiesa R, Coppi G, et al. Editor's choice - management of descending thoracic aorta diseases: clinical practice guidelines of the european society for vascular surgery (ESVS). Eur J Vasc Endovasc Surg. 2017;53:4-52.

7. Nienaber CA, Fattori R, Lund G, Dieckmann C, Wolf W, von Kodolitsch Y, et al. Nonsurgical reconstruction of thoracic aortic dissection by stent-graft placement. N Engl J Med. 1999;340(20):1539-45. https://doi.org/10.1056/ NEJM199905203402003.

8. Clough RE, Taylor PR. A new classification system for aortic dissection. Eur J Vasc Endovasc Surg. 2013;46(2):191. https://doi.org/10.1016/j.ejvs.2013.05. 009.

9. Grabenwoger M, Alfonso F, Bachet J, Bonser R, Czerny M, Eggebrecht $\mathrm{H}$, et al. Thoracic Endovascular Aortic Repair (TEVAR) for the treatment of aortic diseases: a position statement from the European Association for CardioThoracic Surgery (EACTS) and the European Society of Cardiology (ESC), in collaboration with the European Association of Percutaneous Cardiovascular Interventions (EAPCI). Eur J Cardio Thorac Surg. 2012:42:17-24.

10. Fillinger MF, Greenberg RK, McKinsey JF, Chaikof EL, Society for Vascular Surgery Ad Hoc Committee on TRS. Reporting standards for thoracic endovascular aortic repair (TEVAR). J Vasc Surg. 2010;52:1022-33 1033 e15.

11. Kunishige $H$, Myojin K, Ishibashi Y, Ishii K, Kawasaki M, Oka J. Predictors of surgical indications for acute type $B$ aortic dissection based on enlargement of aortic diameter during the chronic phase. Jpn J Thorac Cardiovasc Surg. 2006;54(11):477-82. https://doi.org/10.1007/s11748-006-0039-9. 
12. Marui A, Mochizuki T, Koyama T, Mitsui N. Degree of fusiform dilatation of the proximal descending aorta in type B acute aortic dissection can predict late aortic events. J Thorac Cardiovasc Surg. 2007;134(5):1163-70. https://doi. org/10.1016/j.jtcvs.2007.07.037.

13. Melissano G, Bertoglio L, Rinaldi E, Civilini E, Tshomba Y, Kahlberg A, et al. Volume changes in aortic true and false lumen after the "PETTICOAT" procedure for type B aortic dissection. J Vasc Surg. 2012;55(3):641-51. https://doi.org/10.1016/j.jvs.2011.10.025.

14. Fujikawa T, Yamamoto S, Sekine Y, Oshima S, Kasai R, Mochida Y, et al. Operative results and clinical features of chronic Stanford type B aortic dissection: examination of 234 patients over 6 years. Eur J Vasc Endovasc Surg. 2015;50(6):738-43. https://doi.org/10.1016/j.ejvs.2015.07.012.

15. Patterson BO, Cobb RJ, Karthikesalingam A, Holt PJ, Hinchliffe RJ, Loftus IM, et al. A systematic review of aortic remodeling after endovascular repair of type B aortic dissection: methods and outcomes. Ann Thorac Surg. 2014; 97(2):588-95. https://doi.org/10.1016/j.athoracsur.2013.07.128.

16. Tang JD, Huang JF, Zuo KQ, Hang WZ, Yang MF, Fu WG, et al. Emergency endovascular repair of complicated Stanford type B aortic dissections within 24 hours of symptom onset in 30 cases. J Thorac Cardiovasc Surg. 2011; 141(4):926-31. https://doi.org/10.1016/j.jtcvs.2010.05.038.

17. Nienaber CA. Influence and critique of the INSTEAD trial (TEVAR versus medical treatment for uncomplicated type B aortic dissection). Semin Vasc Surg. 2011;24(3):167-71. https://doi.org/10.1053/j.semvascsurg.2011.10.003.

18. Sayer D, Bratby M, Brooks M, Loftus I, Morgan R, Thompson M. Aortic morphology following endovascular repair of acute and chronic type B aortic dissection: implications for management. Eur J Vasc Endovasc Surg. 2008;36(5):522-9. https://doi.org/10.1016/j.ejvs.2008.06.023.

19. Menichini C, Cheng Z, Gibbs RGJ, Xu XY. A computational model for false lumen thrombosis in type B aortic dissection following thoracic endovascular repair. J Biomech. 2018;66:36-43. https://doi.org/10.1016/j. jbiomech.2017.10.029.

20. Tsai TT, Schlicht MS, Khanafer K, Bull JL, Valassis DT, Williams DM, et al. Tear size and location impacts false lumen pressure in an ex vivo model of chronic type B aortic dissection. J Vasc Surg. 2008;47(4):844-51. https://doi. org/10.1016/j.jvs.2007.11.059.

21. Tolenaar JL, van Keulen JW, Trimarchi S, Jonker FHW, van Herwaarden JA, Verhagen HJM, et al. Number of entry tears is associated with aortic growth in type B dissections. Ann Thorac Surg. 2013;96(1):39-42. https://doi.org/10.1 016/j.athoracsur.2013.03.087.

22. Cochennec F, Tresson P, Cross J, Desgranges P, Allaire E, Becquemin JP. Hybrid repair of aortic arch dissections. J Vasc Surg. 2013;57(6):1560-7. https://doi.org/10.1016/j.jvs.2012.11.081.

23. Vallerio P, Maloberti A, D'Alessio I, Lista A, Varrenti M, Castelnuovo S, et al. Cardiovascular remodeling after endovascular treatment for thoracic aortic injury. Ann Vasc Surg. 2019;61:134-41. https://doi.org/10.1016/j.avsg.2019.04. 015.

\section{Publisher's Note}

Springer Nature remains neutral with regard to jurisdictional claims in published maps and institutional affiliations.

\section{Ready to submit your research? Choose BMC and benefit from}

- fast, convenient online submission

- thorough peer review by experienced researchers in your field

- rapid publication on acceptance

- support for research data, including large and complex data types

- gold Open Access which fosters wider collaboration and increased citations

- maximum visibility for your research: over $100 \mathrm{M}$ website views per year

At $\mathrm{BMC}$, research is always in progress.

Learn more biomedcentral.com/submissions 